\title{
Cripto-1 overexpression is involved in the tumorigenesis of gastric-type and pancreatobiliary-type intraductal papillary mucinous neoplasms of the pancreas
}

\author{
SUNG P. HONG ${ }^{1}$, EUN K. LEE ${ }^{2}$, JEONG Y. PARK ${ }^{1}$, TAE J. JEON $^{3}$, SEUNGMIN BANG ${ }^{1}$, \\ SEUNGWOO PARK ${ }^{1}$, JAE B. CHUNG ${ }^{1}$, WOO J. LEE ${ }^{4}$, HOGUEN KIM ${ }^{5}$ and SI Y. SONG ${ }^{1,2}$ \\ ${ }^{1}$ Division of Gastroenterology, Department of Internal Medicine, ${ }^{2}$ Brain Korea 21 Project for Medical \\ Science, ${ }^{4}$ Department of Surgery, ${ }^{5}$ Department of Pathology, Yonsei Institute of Gastroenterology, \\ Yonsei University College of Medicine, Division of Gastroenterology, ${ }^{3}$ Department of Internal \\ Medicine, Sanggye Paik Hospital, Inje University College of Medicine, Seoul, Korea
}

Received June 2, 2008; Accepted July 15, 2008

DOI: 10.3892/or_00000184

\begin{abstract}
Human Cripto-1, a membrane-bound protein, plays an important role during early embryogenesis and has oncogenic properties, including cell transformation and enhancement of invasion. Cripto- 1 is up-regulated in various malignant tissues and premalignant lesions. However, Cripto-1 expression in intraductal papillary mucinous neoplasms (IPMNs) has yet to be reported. This study aimed to investigate Cripto-1 expression in IPMNs and evaluate the expression patterns according to the histological grade or phenotypic subclassification. Cripto-1 expression was evaluated by immunohistochemistry using 37 IPMN tissue samples and real-time RT-PCR analysis of seven frozen samples. Cripto-1 was up-regulated in 59.5\% of IPMNs. Cripto-1 was positively stained in 3 of $4(75 \%)$ adenomas, 12 of $19(63.2 \%)$ borderline neoplasms, 5 of $11(45.5 \%)$ non-invasive carcinomas and 2 of $3(66.7 \%)$ invasive carcinomas. There was no correlation between Cripto-1 overexpression and the histological grade $(\mathrm{P}>0.05)$. Cripto-1 expression was significantly increased in pancreatobiliary- $(4 / 5,80 \%)$ and gastric-type $(13 / 19,68.4 .2 \%)$ IPMNs compared with those of the intestinal type (2/10, 20\%; $\mathrm{P}<0.01)$. Cripto-1 mRNA expression was higher in gastricand pancreatobiliary-type IPMNs than in intestinal ones, supporting the immunohistochemical results. It is concluded that Cripto-1 overexpression is involved in the tumorigenesis of gastric- and pancreatobiliary-type IPMNs.
\end{abstract}

Correspondence to: Dr Si Young Song, Department of Internal Medicine, Yonsei University College of Medicine, 134 ShinchonDong, Seodaemun-Gu, 120-752 Seoul, Korea

E-mail: sysong@yumc.yonsei.ac.kr

Key words: intraductal papillary mucinous neoplasm, Cripto-1, immunohistochemistry, real-time RT-PCR, tumorigenesis

\section{Introduction}

The intraductal papillary mucinous neoplasm (IPMN) of the pancreas is a unique pancreatic neoplasm involving main and/ or branch pancreatic ducts (1). IPMN is characterized by the intraductal papillary proliferation of neoplastic mucinous epithelium and cystic dilatation of the pancreatic ducts $(2,3)$. The spectrum of IPMNs includes benign and malignant lesions, which are identified as adenomas, borderline tumors and carcinomas. Of note to us was the more favorable prognosis of IPMNs compared to pancreatic ductal adenocarcinomas, especially their tumorigenesis (3).

IPMNs have been classified into four subtypes based on histological phenotypes and the expression of mucin core protein (MUC) (4). The gastric-type IPMN resembles gastric foveloar epithelium with a negative expression of MUC1 and MUC2. The intestinal-type IPMN consists of cells resembling intestinal villous neoplasms with tall columnar epithelial cells and shows a positive expression of MUC2. The pancreatobiliary type of IPMN shows cholangiopapillary neoplasms with a positive expression of MUC1. The oncocytic type of IPMN consists of cells with abundant and intensely eosinophilic cytoplasm and shows a focal positive expression of MUC1. Although the IPMN subtypes show distinct phenotypic and histological differences, the carcinogenic differences between subtypes have been poorly studied.

Human Cripto-1 is a member of the epidermal growth factor-Cripto-FRL-Criptic (EGF-CFC) family, which includes mouse Cripto-1, cryptic Xenopus FRL-1, zebrafish one-eyedpinhead (oep) and chick Cripto (5). Cripto-1 is a membranebound protein, anchored by glycosylphosphatidylinositol, and acts as a cell surface co-receptor (5-7). Cripto-1 functions as a soluble protein after cleavage of the glycosylphosphatidylinositol linkage (8). EGF-CFC proteins play an important role in the formation of the mesoderm and endoderm during gastrulation and are essential for cell movements that correctly orient the embryo along the anterior/posterior and left/right axes in embryogenesis $(5,9)$. Cripto- 1 also functions as an 
oncogene involved in in vitro cellular transformation and enhancement of cancer cell proliferation, migration, invasion and angiogenesis (10-12). It is highly expressed in various malignancies, including stomach, colon, breast, lung and pancreatic cancer (13-16), and overexpressed in premalignant lesions and early stage gastric and colon cancer, suggesting its activation plays an important role in the early stages of carcinogenesis $(17,18)$.

The present study aimed to analyze the Cripto- 1 expression in surgical IPMN specimens using immunohistochemical staining and real-time RT-PCR, to clarify its relationship with the histological grade and phenotypic subtype, and to elucidate the association between Cripto-1 expression and IPMN tumorigenesis.

\section{Materials and methods}

Patients and tissue specimens. A total of 37 IPMN specimens were used for the present study. The IPMNs were surgically resected at Yonsei University Medical Center between 1990 and 2005. For the histopathological diagnosis, specimens were paraffin-embedded and stained with hematoxylin and eosin (H\&E). According to the World Health Organization (WHO) classification scheme, the lesions were classified as adenomas, borderline neoplasms, non-invasive carcinomas or invasive carcinomas on the basis of the greatest degree of dysplasia. In accordance with the suggested subclassification system, the lesions were subclassified into: gastric, intestinal, pancreatobiliary and oncocytic types, based on their histological phenotype and immunohistochemical expression of the MUC protein (gastric type $\mathrm{MUC1}^{-/} \mathrm{MUC2}^{-}$, intestinal type MUC1/MUC2 ${ }^{+}$, pancreatobiliary type $\mathrm{MUC1}^{+} / \mathrm{MUC2}^{-}$and oncocytic type $\mathrm{MUC1}^{+} / \mathrm{MUC2}^{-}$) (4). IPMNs that were not categorized specifically into one of the above four subtypes were segregated into an unclassified type. Two samples from normal pancreatic tissue and five samples from chronic pancreatitis tissue were included in the study for comparison. The Ethics Committee for Clinical Research of the Institutional Review Board of Yonsei Medical Center, Korea, approved the study protocol.

Immunohistochemical staining. The primary antibodies used were: anti-Cripto-1 (89646, monoclonal, R\&D systems, Minneapolis, USA; 1:200 dilution), anti-MUC1 (Ma552, monoclonal, Novocastra Laboratories, Newcastle upon Tyne, UK; 1:200 dilution) and anti-MUC2 (H-300, polyclonal, Santa Cruz Biotechnology, Santa Cruz, CA, USA; 1:200 dilution). Formalin-fixed, paraffin-embedded tissues were cut into $4 \mu \mathrm{m}$ sections, deparaffinized with xylene and rehydrated with graded alcohol. Endogenous peroxidase activity was blocked by incubating slides at room temperature for $15 \mathrm{~min}$ in methanol containing 3\% hydrogen peroxide. Microwave antigen retrieval was performed in citrate buffer $(0.01 \mathrm{M}$, $\mathrm{pH} \mathrm{6.0)} \mathrm{for} 10 \mathrm{~min}$. To reduce non-specific staining, slides were incubated with $10 \%$ normal donkey serum solution for $30 \mathrm{~min}$. Blocked sections were incubated in primary antibody overnight at $4^{\circ} \mathrm{C}$ and stained with a streptavidin-biotin peroxidase kit according to the manufacturer's protocol. Slides were developed by incubating with 3-amino-9-ethyl carbazole and counterstained with hematoxylin. Breast cancer tissue was used as a positive control. A negative control was created by applying secondary antibody without primary antibody.

Evaluation of immunohistochemical staining of Cripto-1. The immunohistochemical staining of Cripto-1 was evaluated within the area showing the highest degree of dysplasia in each IPMN. Samples were evaluated by two pathologists who did not have any knowledge of patient clinical information. We scored samples according to the percentage of Cripto- 1 positive tumor cells as: $<10 \%, 0 ; 10-25 \%, 1+; 25-50 \%, 2+$ and $>50 \%, 3+$. Scores of $2+$ and $3+$ were regarded as being indicative of the positive expression of Cripto-1.

Real-time RT-PCR. For analysis by real-time RT-PCR, three normal pancreas specimens from ampullary tumors and seven IPMN specimens were obtained. Total RNA was extracted using an RNeasy mini kit (Qiagen, Hilden, Germany) and cDNA was synthesized using the Superscript II system (Invitrogen, Carlsbad, CA, USA) as described previously (19). Quantification of Cripto-1 mRNA was conducted using the SYBR-Green RT-PCR kit (Invitrogen) and ABI PRISM 7300 sequence detector (Applied BioSystems, Foster City, CA) according to the manufacturers' instructions. In brief, the total volume of the reaction mixture was $25 \mu 1$, containing $12.5 \mu \mathrm{l}$ of SYBR-Green qRCR Supermix (Invitrogen), 5 pmol of sense and antisense primer and $5 \mu 1$ of cDNA. The reaction was run online at $50^{\circ} \mathrm{C}$ for $2 \mathrm{~min}$ and $95^{\circ} \mathrm{C}$ for $10 \mathrm{~min}$, followed by 40 cycles at $95^{\circ} \mathrm{C}$ for $15 \mathrm{sec}$ and $60^{\circ} \mathrm{C}$ for $60 \mathrm{sec}$. After real-time $\mathrm{PCR}$, the temperature was increased from 60 to $95^{\circ} \mathrm{C}$ at a rate of $2^{\circ} \mathrm{C} / \mathrm{min}$ to construct a melting curve. The results were analyzed with the melting curve analysis software (Dissociation Curve 1.0; Applied BioSystems) provided with the ABI PRISM 7300 sequence detector. The expression of Cripto-1 mRNA was normalized to that of the reference gene, RPL13A (20). Relative quantification of Cripto-1 mRNA within the samples examined was performed using the comparative $\mathrm{Ct}$ method $\left(\Delta \mathrm{Ct}_{\text {sample }}-\Delta \mathrm{Ct}_{\text {calibrator }}=\Delta \Delta \mathrm{Ct}\right.$; relative quantity $\left.=2^{-\Delta \Delta \mathrm{Ct}}\right)(21)$. The primers used were: Cripto-1 forward: 5'-TGGCCCGCTTCTCTTACAGTG-3' and reverse: 5'-CCCCGAGATGGACGAGCAAAT-3'; and RPL13A forward: 5'-GGCCCAGCAGTACCTGTTTA-3' and reverse: 5'-AGATGGCGGAGGTGCAG-3'.

Statistical analysis. Fisher's exact test was used to compare Cripto-1 expression with the histological grades and subtypes. The Cripto-1 expression scores were compared with the histological grades using Spearman's correlation and subtypes using Pearson's methods. The IPMN subtypes and Cripto-1 expression were compared with clinicopathological parameters using Fisher's exact and Mann-Whitney U-tests.

\section{Results}

Clinicopathological features and phenotypic subclassification. The clinicopathological findings from the 37 cases are summarized in Table I. Of 37 cases, 4 (10.8\%) were classified as adenomas, $19(51.4 \%)$ as borderline neoplasms, 11 (29.7\%) as non-invasive carcinomas and $3(8.1 \%)$ as invasive carcinomas (Table I). According to the phenotypic subclassification, $19(51.4 \%)$ were subclassified as gastric, $10(27 \%)$ as 
Table I. Patient characteristics.

\begin{tabular}{lc}
\hline Variables & No. of patients $(\%)$ \\
\hline Total & 37 \\
Age (years) & \\
Median (range) & $61(42-73)$ \\
Gender & \\
Male & $24(64.9)$ \\
Female & $13(35.1)$ \\
Site & \\
Head & $30(81.1)$ \\
Body and/or tail & $7(18.9)$ \\
Tumor size (cm) & \\
Median (range) & $3(0.5-8.5)$ \\
Tumor type & \\
Main duct & $26(70.3)$ \\
Branch duct & $11(29.7)$ \\
Histological grade & \\
(WHO classification) & \\
Adenoma & $19(51.4)$ \\
Borderline neoplasm & \\
Carcinoma & \\
Non-invasive & \\
Invasive & $(10.8)$ \\
\hline
\end{tabular}

intestinal, $5(13.5 \%)$ as pancreatobiliary, $1(2.7 \%)$ as oncocytic and $2(5.4 \%)$ as unclassified types (Table II, Fig. 1). Intestinaland pancreatobiliary-type IPMNs showed a significantly increased histological grade compared to the gastric ones $(\mathrm{P}<0.001$; Table II). Branch duct-type IPMNs were more frequent in gastric type $(47.7 \%)$ than other types $(11.1 \%$; $\mathrm{P}<0.05$, data not shown). Gastric-type IPMNs (median diameter, $27.5 \mathrm{~mm}$ ) were significantly smaller than intestinal
$(35 \mathrm{~mm})$ and pancreatobiliary types $(52.5 \mathrm{~mm} ; \mathrm{P}<0.05$, data not shown).

Immunohistochemical expression of Cripto-1. Cripto-1 was stained diffusely in the cytoplasm. It was not expressed in acinar and ductal cells in the normal pancreatic specimens, but was weakly expressed in the cytoplasm of metaplastic duct cells in chronic pancreatitis. Of 37 IPMNs, $22(59.5 \%)$ demonstrated a positive immunohistochemical expression of Cripto-1 (Table III). According to the histological grade, 3 of $4(75 \%)$ adenomas, 12 of $19(63.2 \%)$ borderline neoplasms, 5 of $11(45.5 \%)$ non-invasive carcinomas and 2 of $3(66.7 \%)$ invasive carcinomas showed positive staining of Cripto- 1 . No correlation between the histological grade and Cripto-1 overexpression ( $\mathrm{P}>0.05$ ) was found. However, Cripto-1 overexpression differed among the subtypes (Fig. 2). Compared to the intestinal type $(2 / 10,20 \%)$, Cripto- 1 expression was significantly more frequent in gastric- and pancreatobiliarytype $(13 / 19,68.4 \%$ and $4 / 5,80 \%$, respectively) IPMNs $(\mathrm{P}<0.01$; Table III). One case of oncocytic type and two of unclassified type were positive for Cripto-1. Immunohistochemical results showed no difference in Cripto- 1 expression between the main duct- and branch duct-type IPMNs $(57.7 \%$ vs. $63.6 \%, \mathrm{P}>0.05)$.

Cripto-1 mRNA expression. For the quantitative analysis of Cripto-1 mRNA expression, real-time RT-PCR was performed. Seven frozen specimens were used ( 2 adenomas, 2 borderline neoplasms, 1 carcinoma and 2 invasive carinomas). According to the phenotypic subclassification, 3 gastric, 2 intestinal and 2 pancreatobiliary-type specimens were used. Three normal pancreatic specimens from ampullary tumors were used to analyze the relative expression of Cripto-1.

The relative expression of Cripto- 1 mRNA was elevated in IPMNs compared to normal pancreas (Fig. 3). There was no correlation between histological progression and Cripto-1 mRNA expression. Cripto-1 mRNA was overexpressed in gastric- and pancreatobiliary-type IPMNs compared with the intestinal ones. The results of real-time RT-PCR analysis were consistent with those from immunohistochemical staining.

Table II. Phenotypic subclassification and histological progression of IPMNs.

\begin{tabular}{|c|c|c|c|c|c|c|}
\hline & \multicolumn{4}{|c|}{ Histological progression $\mathrm{n}(\%)$} & \multirow[b]{3}{*}{ Total } & \multirow[b]{3}{*}{$\mathrm{P}$} \\
\hline & \multirow[b]{2}{*}{ Adenoma } & \multirow[b]{2}{*}{ Borderline } & \multicolumn{2}{|c|}{ Carcinoma } & & \\
\hline & & & Non-invasive & Invasive & & \\
\hline Subtype & & & & & & $<0.001$ \\
\hline $\mathrm{G}$ & $4(21.1)$ & $14(73.7)$ & $1(5.3)$ & $0(0)$ & $19(51.4)$ & \\
\hline $\mathrm{I}^{\mathrm{a}}$ & $0(0)$ & $4(40)$ & $5(50)$ & $1(10)$ & $10(27.0)$ & \\
\hline $\mathrm{PB}^{\mathrm{a}}$ & $0(0)$ & $0(0)$ & $4(80)$ & $1(20)$ & $5(13.5)$ & \\
\hline $\mathrm{O}$ & $0(0)$ & $0(0)$ & $0(0)$ & $1(100)$ & $1(2.70)$ & \\
\hline $\mathrm{U}$ & 0 & $1(50)$ & $1(50)$ & $0(0)$ & $2(5.40)$ & \\
\hline
\end{tabular}

G, gastric; I, intestinal; $\mathrm{PB}$, pancreatobiliary; $\mathrm{O}$, oncocytic and $\mathrm{U}$, unclassified type. ${ }^{\mathrm{a}} \mathrm{P}<0.001$, compared with gastric type, using Fisher's exact test. 

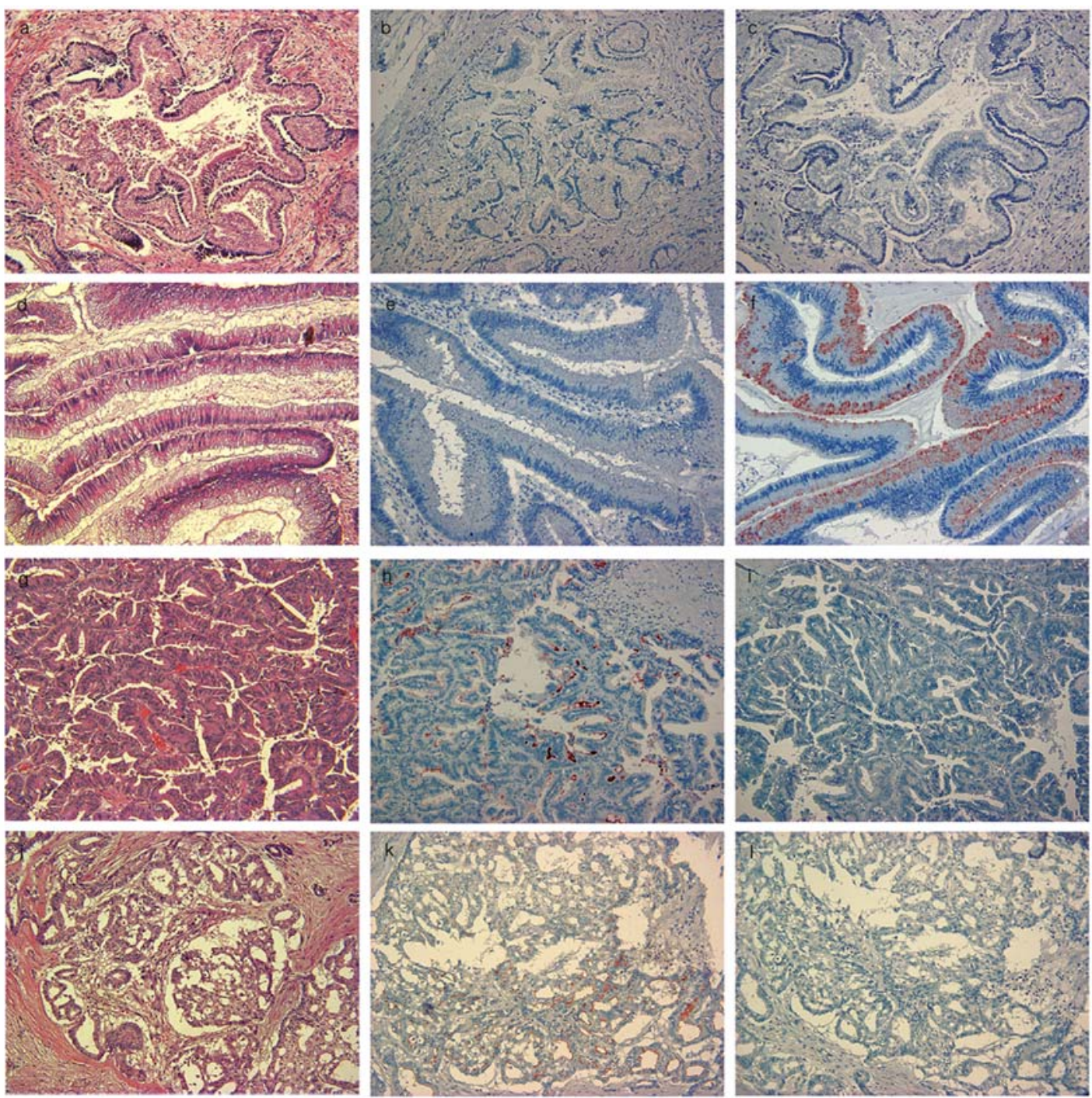

Figure 1. Representative images of the subtypes of intraductal papillary mucinous neoplasms of the pancreas (IPMN) stained with H\&E (a, d, g and j), MUC1 (b, e, h and k) and MUC2 (c, f, i and 1). (a, b and c) Adenoma of gastric type with negative staining of MUC1 and MUC2. (d, e and f) Borderline neoplasm of intestinal type with positive staining of MUC2 and negative staining of MUC1. ( $g$, h and i) Carcinoma of pancreatobiliary type with positive staining of MUC1 and negative staining of MUC2. (j, k and 1) Carcinoma of oncocytic type with a focal positive expression of MUC1 and negative staining of MUC2.

\section{Discussion}

Cripto-1 shows oncogenic properties as demonstrated by the in vitro cellular transformation of several mouse cell lines and in vivo mammary tumorigenesis in transgenic mice stably overexpressing a human Cripto-1 transgene in the mammary gland $(10,11,22-24)$. However, the precise function of Cripto-1 in carcinogenesis is not fully understood. Studies have demonstrated that Cripto-1 interacts with glypican-1, a membrane-associated heparin sulfate proteoglycan, and activates the cytoplasmic tyrosine kinase c-src $(25,26)$, which triggers the ras/raf/mitogen-activated protein kinase (MAPK) pathway (27) and phosphatidylinositol 3'-kinase/Akt pathway (28). In addition, Cripto- 1 directly binds activin B and inhibits activin signaling, which acts as a potent tumor suppressor (30). Several studies have also demonstrated that Cripto-1 may be involved in the early stages of carcinogenesis in different tissues. In MMTV/Cripto-1 transgenic mice, Cripto-1 overexpression induced mammary intraductal hyper- plasia and papillary adenocarcinomas $(23,24)$. Cripto- 1 expression also significantly increases in several premalignant lesions, including gastric intestinal metaplasia, gastric and colon adenomas, and ductal carcinomas in situ of the breast $(18,30,31)$. In the present study, Cripto-1 expression significantly increased in adenomas and borderline neoplasms of the IPMN type, which means that Cripto-1 may be activated in an early stage of IPMN tumorigenesis.

A proposal made for the phenotypic subclassification of IPMNs was an effort to better understand the biological behavior of IPMNs and their clinical management (4). Our results, when utilizing the phenotypic subclassification, demonstrated that gastric types usually showed mild dysplasia and were frequently associated with branch duct types. Intestinal types showed moderate to severe dysplasia, whereas pancreatobiliary types showed severe dysplasia, which was consistent with a previous report (4). The IPMN subtypes showed differential immunohistochemical staining of MUC, which implies diversity in the tumor progression pathway. 

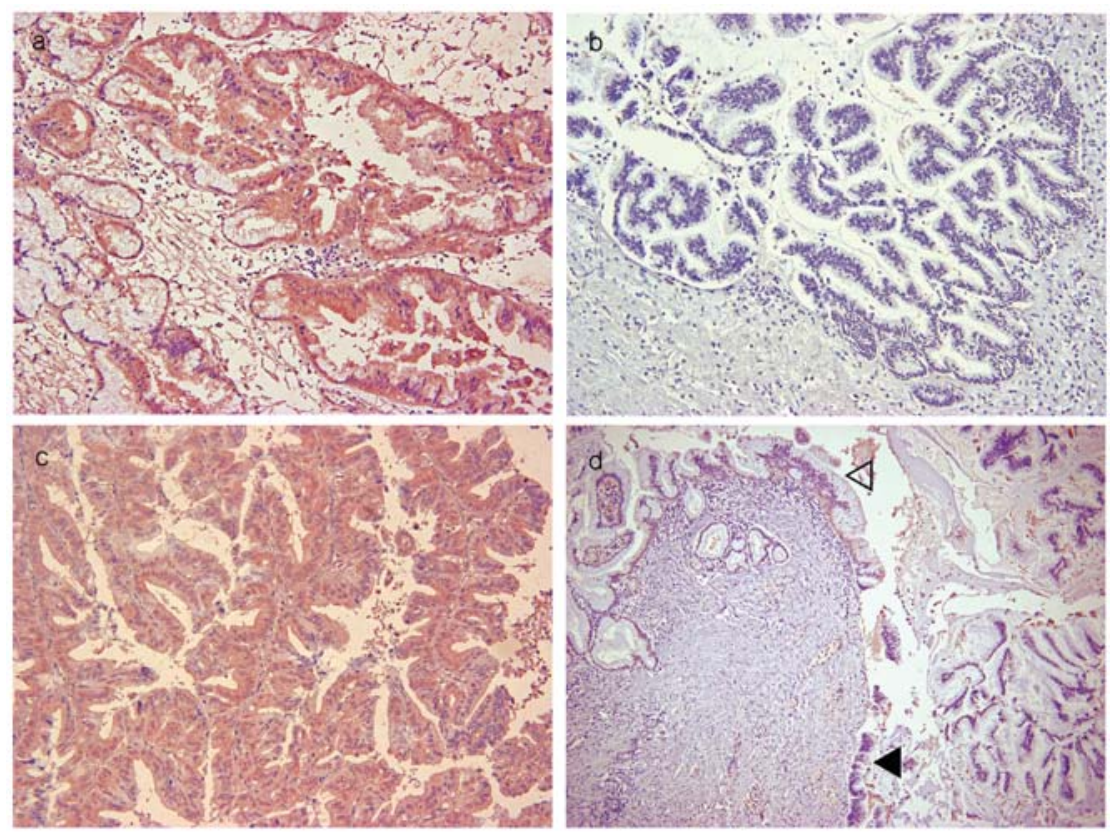

Figure 2. Cripto-1 expression using immunohistochemistry. (a) Positive case of gastric-type adenoma (score 3). (b) Negative case of intestinal-type borderline neoplasm (score 0). (c) Positive case of pancreatobiliary-type carcinoma (score 3). (d) Diffuse positive staining in a localized gastric type (white arrowhead) and negative staining in the main intestinal-type borderline neoplasm (black arrowhead).

Table III. Cripto-1 expression according to histological progression and phenotypic subtype.

\begin{tabular}{lccc}
\hline & \multicolumn{3}{c}{ Cripto-1 expression } \\
\cline { 2 - 4 } & Negative (\%) & Positive (\%) & $\mathrm{P}$ \\
\hline Histological grade & & & $>0.05$ \\
$\quad$ Adenoma & $1(25)$ & $3(75)$ & \\
Borderline $^{\mathrm{a}}$ & $7(36.8)$ & $12(63.2)$ & \\
Carcinoma $^{\mathrm{a}}$ & & & \\
Non-invasive $_{\text {Invasive }}$ & $6(54.5)$ & $5(45.5)$ & \\
Phenotypic subtype & $1(33.3)$ & $2(66.7)$ & \\
G & & & $<0.01$ \\
I & $6(31.6)$ & $13(68.4)$ & \\
PB & $8(80)$ & $2(20)$ & \\
O & $1(20)$ & $4(80)$ & \\
U & $0(0)$ & $1(100)$ & \\
Total & $0(0)$ & $2(100)$ & \\
\hline & $15(40.5)$ & $22(59.5)$ & \\
\hline
\end{tabular}

$\mathrm{G}$, gastric; I, intestinal; $\mathrm{PB}$, pancreatobiliary; O, oncocytic and $\mathrm{U}$, unclassified type. ${ }^{\text {a }}>0.05$, compared with adenoma, using Spearman's correlation. ${ }^{\mathrm{b}} \mathrm{P}<0.01$, compared with gastric and pancreatobiliary types, using Pearson's method.

The pancreatobiliary type shows a positive expression of MUC 1, which correlates with histological progression in invasive ductal adenocarcinoma (32). MUC2 is expressed mainly in goblet cells of the intestine, which means intestinal

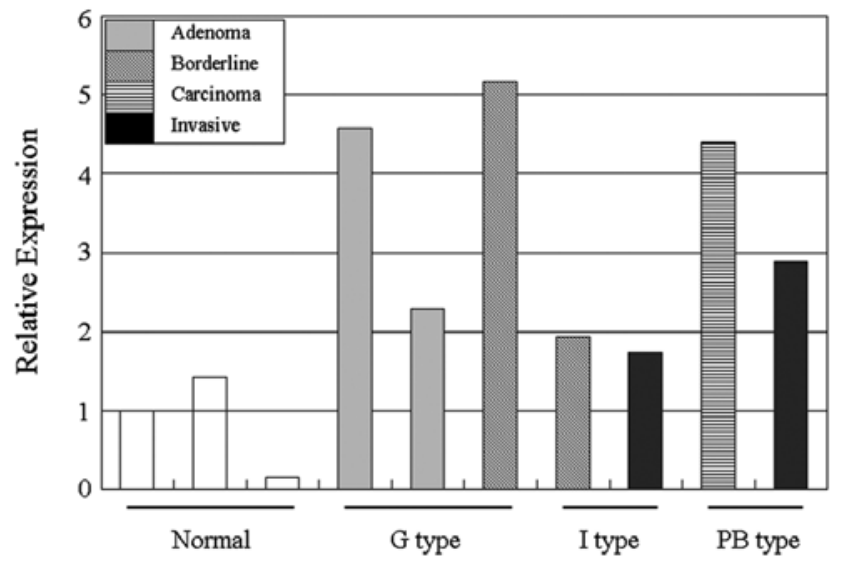

Figure 3. Real-time RT-PCR in 3 normal pancreas samples and 7 IPMN samples. Relative quantification of Cripto-1 mRNA was performed using the comparative $\mathrm{Ct}$ method. Cripto-1 mRNA significantly increased in IPMNs compared with normal pancreas, and in gastric- and pancreatobiliarytype IPMNs compared with intestinal ones. G, gastric; I, intestinal and PB, pancreatobiliary type.

differentiation is important in this subtype (33-35). Our results show that Cripto-1 expression was significantly more frequent in gastric- and pancreatobiliary-type IPMNs compared with intestinal ones. These results support the possibility that the IPMN subtypes may have different carcinogenic pathways.

In conclusion, we demonstrated that Cripto-1 is overexpressed in the relatively early stages of IPMN progression and is significantly up-regulated in gastric- and pancreatobiliary-type IPMNs. Cripto-1 may be used as an early diagnostic marker of IPMNs, which have been studied in breast and colon cancer, and may be a new therapeutic molecular target of inhibiting the progression of IPMNs $(36,37)$. 


\section{References}

1. Sessa F, Solcia E, Capella C, et al: Intraductal papillarymucinous tumours represent a distinct group of pancreatic neoplasms: an investigation of tumour cell differentiation and K-ras, p53 and c-erbB-2 abnormalities in 26 patients. Virchows Arch 425: 357-367, 1994.

2. Rickaert F, Cremer M, Devière J, et al: Intraductal mucinhypersecreting neoplasms of the pancreas. A clinicopathologic study of eight patients. Gastroenterology 101: 512-519, 1991.

3. Sugiyama M and Atomi Y: Intraductal papillary mucinous tumors of the pancreas: imaging studies and treatment strategies. Ann Surg 228: 685-691, 1998.

4. Furukawa T, Klöppel G, Volkan Adsay N, et al: Classification of types of intraductal papillary-mucinous neoplasm of the pancreas: a consensus study. Virchows Arch 447: 794-799, 2005.

5. Shen MM and Schier AF: The EGF-CFC gene family in vertebrate development. Trends Genet 16: 303-309, 2000.

6. Minchiotti G, Parisi S, Liguori G, et al: Membrane-anchorage of Cripto protein by glycosylphosphatidylinositol and its distribution during early mouse development. Mech Dev 90: 133-142, 2000.

7. Yan YT, Liu JJ, Luo Y, et al: Dual roles of Cripto as a ligand and coreceptor in the nodal signaling pathway. Mol Cell Biol 22: 4439-4449, 2002.

8. Saloman DS, Bianco C, Ebert AD, et al: The EGF-CFC family: novel epidermal growth factor-related proteins in development and cancer. Endocr Relat Cancer 7: 199-226, 2000.

9. Schier AF: Nodal signaling in vertebrate development. Annu Rev Cell Dev Biol 19: 589-621, 2003.

10. Ciardiello F, Dono R, Kim N, Persico MG and Salomon DS: Expression of cripto, a novel gene of the epidermal growth factor gene family, leads to in vitro transformation of a normal mouse mammary epithelial cell line. Cancer Res 51: 1051-1054, 1991.

11. Wechselberger C, Ebert AD, Bianco C, et al: Cripto-1 enhances migration and branching morphogenesis of mouse mammary epithelial cells. Exp Cell Res 266: 95-105, 2001.

12. Bianco C, Strizzi L, Ebert A, et al: Role of human cripto-1 in tumor angiogenesis. J Natl Cancer Inst 97: 132-141, 2005.

13. Ciardiello F, Kim N, Saeki T, et al: Differential expression of epidermal growth factor-related proteins in human colorectal tumors. Proc Natl Acad Sci USA 88: 7792-7796, 1991.

14. Qi CF, Liscia DS, Normanno N, et al: Expression of transforming growth factor alpha, amphiregulin and cripto-1 in human breast carcinomas. Br J Cancer 69: 903-910, 1994.

15. Fontanini G, De Laurentiis M, Vignati S, et al: Evaluation of epidermal growth factor-related growth factors and receptors and of neoangiogenesis in completely resected stage I-IIIA nonsmall-cell lung cancer: amphiregulin and microvessel count are independent prognostic indicators of survival. Clin Cancer Res 4: 241-249, 1998.

16. Friess H, Yamanaka Y, Büchler M, Kobrin MS, Tahara E and Korc M: Cripto, a member of the epidermal growth factor family, is over-expressed in human pancreatic cancer and chronic pancreatitis. Int J Cancer 56: 668-674, 1994.

17. Allgayer $\mathrm{H}$, Heiss MM and Schildberg FW: Prognostic factors in gastric cancer. Br J Surg 84: 1651-1664, 1997.

18. Saeki T, Stromberg K, Qi CF, et al: Differential immunohistochemical detection of amphiregulin and cripto in human normal colon and colorectal tumors. Cancer Res 52: 3467-3473, 1992.

19. Kim HS, Park KH, Kim SA, et al: Frequent mutations of human Mad2, but not Bub1, in gastric cancers cause defective mitotic spindle checkpoint. Mutat Res 578: 187-201, 2005.
20. Jesnowski R, Backhaus C, Ringel J and Lohr M: Ribosomal highly basic $23-\mathrm{kDa}$ protein as a reliable standard for gene expression analysis. Pancreatology 2: 421-424, 2002.

21. Kim JJ, Li JJ, Jung DS, et al: Differential expression of nephrin according to glomerular size in early diabetic kidney disease. J Am Soc Nephrol 18: 2303-2310, 2007.

22. Niemeyer CC, Persico MG and Adamson ED: Cripto: roles in mammary cell growth, survival, differentiation and transformation. Cell Death Differ 5: 440-449, 1998.

23. Strizzi L, Bianco C, Normanno N, et al: Epithelial mesenchymal transition is a characteristic of hyperplasias and tumors in mammary gland from MMTV-Cripto-1 transgenic mice. J Cell Physiol 201: 266-276, 2004.

24. Wechselberger C, Strizzi L, Kenney N, et al: Human Cripto-1 overexpression in the mouse mammary gland results in the development of hyperplasia and adenocarcinoma. Oncogene 24: 4094-4105, 2005.

25. Park PW, Reizes O and Bernfield M: Cell surface heparan sulfate proteoglycans: selective regulators of ligand-receptor encounters. J Biol Chem 275: 29923-29926, 2000.

26. Bianco C, Strizzi L, Rehman A, et al: A nodal- and ALK4independent signaling pathway activated by Cripto- 1 through glypican-1 and c-src. Cancer Res 63: 1192-1197, 2003.

27. Kannan S, De Santis M, Lohmeyer M, et al: Cripto enhances the tyrosine phosphorylation of Shc and activates mitogenactivated protein kinase (MAPK) in mammary epithelial cells. J Biol Chem 272: 3330-3335, 1997.

28. Ebert AD, Wechselberger C, Frank S, et al: Cripto-1 induces phosphatidylinositol 3'-kinase-dependent phosphorylation of $\mathrm{AKT}$ and glycogen synthase kinase 3 beta in human cervical carcinoma cells. Cancer Res 59: 4502-4505, 1999.

29. Gray PC, Harrison CA and Vale W: Cripto forms a complex with activin and type II activin receptors and can block activin signaling. Proc Natl Acad Sci USA 100: 5193-5198, 2003.

30. Kuniyasu H, Yoshida K, Yokozaki H, et al: Expression of cripto, a novel gene of the epidermal growth factor family, in human gastrointestinal carcinomas. Jpn J Cancer Res 82: 969-973, 1991.

31. Normanno N, Kim N, Wen D, et al: Expression of messenger RNA for amphiregulin, heregulin, and cripto-1, three new members of the epidermal growth factor family, in human breast carcinomas. Breast Cancer Res Treat 35: 293-297, 1995.

32. Osako M, Yonezawa S, Siddiki B, et al: Immunohistochemical study of mucin carbohydrates and core proteins in human pancreatic tumors. Cancer 71: 2191-2199, 1993.

33. Gum JR, Byrd JC, Hicks JW, Toribara NW, Lamport DT and Kim YS: Molecular cloning of human intestinal mucin cDNAs. Sequence analysis and evidence for genetic polymorphism. J Biol Chem 264: 6480-6487, 1989.

34. Ho SB, Niehans GA, Lyftogt C, et al: Heterogeneity of mucin gene expression in normal and neoplastic tissues. Cancer Res 53: 641-651, 1993.

35. Nakamura A, Horinouchi M, Goto M, et al: New classification of pancreatic intraductal papillary-mucinous tumour by mucin expression: its relationship with potential for malignancy. J Pathol 197: 201-210, 2002.

36. Bianco C, Strizzi L, Mancino M, et al: Identification of cripto-1 as a novel serologic marker for breast and colon cancer. Clin Cancer Res 12: 5158-5164, 2006.

37. Xing PX, Hu XF, Pietersz GA, Hosick HL and McKenzie IF: Cripto: a novel target for antibody-based cancer immunotherapy. Cancer Res 64: 4018-4023, 2004. 